Territorios 32 / Bogotá, 2015, pp. 35-59

ISSN: 0123-8418

ISSNe: 2215-7484

Procesos de ocupación del territorio, historia urbana y patrimonio (I)

\title{
Paisaje Cultural Cafetero, Patrimonio de la Humanidad. La cuestión del discurso patrimonial en contraste con el paisaje de la caficultura
}

Coffee Cultural Landscape-World Heritage. Between Patrimonial Discourse and Coffee Cultural Landscape

Paisagem cultural cafeteiro património da humanidade, a questão do discurso patrimonial em contraste com a paisagem da cafeicultura

Diego Alejandro Mayorga Castaño*

Recibido: 15 de septiembre de 2014

Aprobado: 6 de noviembre de 2014

Doi: dx.doi.org/10.12804/territ32.2015.02

Para citar este artículo:

Mayorga, C. D. A. (2015). Paisaje Cultural Cafetero, Patrimonio de la Humanidad. La cuestión del discurso patrimonial en contraste con el paisaje de la caficultura. Territorios, 32, 35-59. Doi: dx.doi.org/10.12804/ * Antropólogo de la Uni-
versidad de Caldas. Inte-
grante del Grupo de inves-
tigación Territorialidades
de la misma universidad
y asistente de investigación
en la Cátedra Unesco de la
Universidad Nacional de
Colombia, sede Manizales.
Correo electrónico: mayor-
dac@gmail.com territ32.2015.02 
Palabras clave

Patrimonio, paisaje, territorio, territorialidad, unidades socio-espaciales, prácticas económicas.

Keywords

Heritage, landscape, territory, territoriality, socio-spatial units, economic practices.

Palavras-chave

Património,

paisagem, território, territorialidade, unidades

socioespaciais, práticas económicas.

\section{territarias 32}

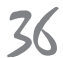

\section{RESUMEN}

En el presente artículo se realizará una comparación entre el paisaje del café, representado bajo el discurso del Paisaje Cultural Cafetero Patrimonio de la Humanidad, y el paisaje reproducido territorialmente por los actores locales. Lo anterior se expresa debido al contraste entre un tipo de paisaje patrimonial, construido desde la mirada institucional, y el paisaje real, reproducido por los actores locales mediante prácticas económicas en las diferentes fincas y haciendas del área rural del municipio de Chinchiná, Caldas - las cuales son concebidas como unidades socio-espaciales de análisis-. La metodología de este trabajo es de naturaleza cualitativa, de corte etnográfica, fundada en las observaciones directas de tipo activo y pasivo, en las entrevistas estructuradas y semiestructuradas y en los talleres con los pobladores de la zona. En los resultados de esta discusión se muestra que la declaratoria es una estrategia para consolidar un tipo de territorio mixto, —café y turismo-. Igualmente, se exhibe etnográficamente la configuración y reconfiguración territorial y económica de la zona rural del municipio de Chinchiná, expresada en las unidades socio-espaciales, lo que evidencia un acercamiento y distanciamiento del discurso de la declaratoria del Paisaje Cultural Cafetero, Patrimonio de la Humanidad.

\section{ABSTRACT}

In this present paper i make a comparison between the coffee landscape represented under the discourse of "Coffee Cultural Landscape-World Heritage" and the territory reproduced territorially by the local actors. This is expressed by the contrast between a certain type of patrimonial landscape built from an institutional sight, and a real landscape produced by the locals through economic practices in the different types of farms of the rural area of the municipality of Chinchiná, which are conceived as socio-spatial units of analysis. The methodology used in this work has a qualitative nature with and ethnographic approximation founded in the direct observations in a passive and active mode, structured and semi-structured interviews, and works in focal groups with the local residents. In the conclusions of this discussion it is showed that the declaratory is an strategy for developing a sort of mixed territory, coffee and tourism; alike, it is ethnographically displayed a territorial and economic configuration and reconfiguration of the rural area of the municipality of Chinchiná-Caldas, expressed in the socio-spatial units, proving an approaching or a distancing from the discourse of the declaratoy of Coffee Cultural Landscape -World Heritage.

\section{RESUMO}

No presente artigo faço uma comparação entre a paisagem do café representado sob o discurso da "Paisagem Cultural Cafeteira Património da Humanidade", e a paisagem reproduzida territorialmente pelos atores locais. O exterior expressa-se através do contraste entre um tipo de paisagem patrimonial construído desde a olhada institucional, e a paisagem real reproduzida pelos atores locais através de práticas económicas nas diferentes fazendas e ranchos da área rural do município de Chinchiná, as quais são concebidas como unidades socioespaciais de análise. A metodologia deste trabalho é de natureza qualitativa de corte etnográfica fundada nas observações diretas de tipo ativo e passivo, as entrevistas estruturadas e semiestruturadas e os workshops com os povoadores da zona. Nos resultados desta discussão mostra-se que a declaratória é uma estratégia para consolidar 
um tipo de território misto, café e turismo; igualmente, exibe etnograficamente a configuração e reconfiguração territorial e econômica da zona rural do município de Chinchiná, Caldas, expressada nas unidades socioespaciais, o que evidencia uma aproximação e/ou afastamento do discurso da declaratória da Paisagem Cultural Cafeteira Património da Humanidade.

\section{Introducción}

El presente artículo es una derivación de la tesis de grado en Antropología Etnografía Territorial de los Procesos de Configuración y Reconfiguración del Paisaje del Café desde una Dimensión Socioeconómica. (Municipio de Chinchiná, Caldas Colombia), desarrollada entre 2012 y 2014. Dicho trabajo está en el marco del proyecto "Cartografía semiótica para la comprensión, análisis y monitoreo del Paisaje Cultural Cafetero como Patrimonio de la Humanidad. El caso de Caldas", ejecutado por el Grupo de Investigación Territorialidades, en asocio con el Instituto de Investigaciones en Ciencias Sociales y Humanas (ICSH) y financiado por la Universidad de Caldas.

El territorio - en diferentes escalas: continente, país, ciudad, veredas, entre otros- como concepto viene siendo, en los últimos años, un tema de suma importancia para comprender fenómenos ligados a la economía, la migración, la patrimonialización y las disputas por obtener un mejor control de los recursos culturales y naturales. En esta medida, se asume que la declaratoria del Paisaje Cultural Cafetero Patrimonio de la Humanidad ${ }^{1}$ (PC$\mathrm{CPH}$ ), aprobada por la Organización de las Naciones Unidas para la Educación, la Ciencia y la Cultura (Unesco), es una de las múltiples estrategias político-económicas acogidas por las instituciones estatales y privadas de orden nacional y mundial, con el fin de representar un sistema paisajístico preponderantemente cafetero, bajo ciertos atributos culturales, históricos, económicos, geográficos, al consolidarlo como un bien patrimonial de valores universales excepcionales. Por tanto, esta tendencia viene siendo un motivo de investigación por parte de académicos de las diferentes ciencias sociales, debido a las implicaciones y reconfiguraciones territoriales que acarrean estos programas políticos de reivindicación cultural y de desarrollo en las múltiples dimensiones de la realidad.

Para abordar lo rural en un marco patrimonial, es pertinente definir los criterios que posibilitaron el acercamiento. Así, el ejercicio de contrastar el PCCPH, elaborado por la institucionalidad representada en la Federación Nacional de Cafeteros de Colombia (FNCC) y el Ministerio de Cultura (Mincultura), con el paisaje real, en el que se reproducen territorialmente estructuras económicas de tipo agrícola, pecuario y del servicio turístico, debe estar transversalizado por categorías analíticas y datos etnográficos. Esto permite poner en evidencia ambos niveles del paisaje. Por un lado, los intereses y proyecciones productivas, que sobre el territorio elaboraron los
${ }^{1}$ Esta declaratoria entra en vigencia a partir de junio del 2011. territarias 32 
actores institucionales (gobierno, sector privado y académicos bajo la figura de comités técnicos regionales), que obedecen a establecer un tipo de sistema cafetero y, al mismo tiempo, un modelo económico basado en el turismo cultural; $y$, por otro lado, se tienen las unidades socio-espaciales, que expresan una serie de configuraciones y reconfiguraciones a nivel territorial, que reflejan un paisaje agro-productivo heterogéneo con bifurcaciones socioeconómicas que pueden responder o contrariar el discurso patrimonial.

\section{Referentes conceptuales y procedimentales}

Teniendo en cuenta la problemática planteada, es necesario referenciar los conceptos que darán soporte al escrito. Al centrarse la discusión en el marco de una declaratoria patrimonial de tipo paisajístico, es pertinente exponer lo que se entiende por patrimonio. El patrimonio, como término polisémico, abarca múltiples rasgos culturales, entre ellos están la herencia, la identidad, las costumbres, las tradiciones y los lugares de las poblaciones, sin embargo, en este caso se parte de que el trasfondo político del patrimonio y su gestión obedecen a intereses colectivos $\mathrm{y} / \mathrm{o}$ particulares, tal como se expresa a continuación:

[...] [El patrimonio] Construcción social, en primer lugar no existe en la naturaleza algo dado, también sucede que es un artificio ideado por alguien, en algún momento, para unos determinados fines, es históricamente cambiante, de acuerdo con nuevos criterios y fines que determinen nuevas circunstancias (Prats, 2004, pp. 19-20).

Es pertinente puntualizar que hay dos modalidades para legitimar o poner en marcha una activación patrimonial. Llorencs Prats (2005) plantea que existen dos tipos de patrimonio, con sus respectivos mecanismos de activación y de cohesión social. Por un lado, hay un patrimonio cultural localizado, el cual está asociado con la institucionalidad, es decir, que está legítimamente aprobado y avalado por los Estados Nacionales, la Unesco, el Centro Internacional de Estudios para la Conservación y la Restauración de los Bienes Culturales (ICCROM), el Consejo Internacional de Monumentos y Sitios (ICOMOS), entre otros. Lo que implica que estos bienes patrimoniales están sujetos a regulaciones por parte de los organismos avaladores, con el objetivo de inspeccionar la conservación y preservación de los valores y atributos culturales expuestos ante la Unesco; además, estos proyectos deben contar con una logística de difusión (medios de comunicaciones) y de operatividad (infraestructura vial, hotelera, mercado de bienes) que faciliten la atracción y posteriormente el tránsito de visitantes para el consumo, en cuanto a hospedaje y mercancías culturales en las áreas declaradas.

Por otro lado, existe el patrimonio local y hace alusión a las localidades sin un patrimonio institucionalmente avalado. Por esta razón, son los mismos pobladores de las comunidades los que ponen en marcha 
sus proyectos patrimoniales, por medio de mecanismos como la memoria, las narrativas y los imaginarios colectivos. Lo anterior, con el objetivo de buscar la conservación y preservación de ciertos valores y prácticas culturales del pasado, para dar significado al presente y proyectarse hacia el futuro. Para esto, deben tener en cuenta ideas, valores e intereses particulares que, por su característica, son cambiantes dependiendo de los contextos que atraviesen (Prats, 2005). Estas apuestas locales procuran por la resignificación o la reivindicación de manifestaciones culturales, costumbres y prácticas, evitando así la desaparición de estas, producto del flujo de tecnología, mercancías y comunicaciones. No obstante, es necesario aclarar que muchos de estos proyectos no escapan a una lógica de producción económica, puesto que en algunos casos, los promotores y demás pobladores usufructúan el patrimonio local.

Al centrar la discusión en un paisaje cultural, es necesario referenciar el concepto de paisaje, puesto que es pieza fundamental del discurso patrimonial. En esta medida, el paisaje no es simplemente la condición física ni perceptiva del entorno, tampoco se pretende plantear un dualismo entre un paisaje natural y un paisaje cultural. Lo que se entiende por paisaje comprende una triada entre espacio, tiempo y tipo de sociedad, tal como se expone a continuación:

Los paisajes no son únicamente la expresión física de la interfaz ser humano-entorno, sino una construcción cultural propia de un momento específico en el espacio y en el tiempo. En otros términos, el análisis de los paisajes y su transformación no se limita a un estudio de las características espaciales y temporales de los cambios físicos, sino también de aquellos relacionados con las sociedades que los moldearon. El paisaje es el escenario en que se reproducen transformaciones permanentes que son resultado de los valores, políticas y condiciones económicas en constante evolución (Guhl, 2009, p. 35 ).

La relación entre las dimensiones espacio, tiempo y tipo de sociedad, evidencia la conjugación de los paisajes, visualizando de esta manera el estrecho vínculo que existe entre lo cultural y lo natural. Así las cosas, los cambios en niveles morfológicos, funcionales y semánticos de los paisajes son producto de la acción discursiva de los actores en diferentes contextos históricos.

No obstante, existen versiones institucionales que definen desde la óptica patrimonial el paisaje. Así pues, el discurso del PCCPH se concibió bajo la categoría lugares, sustentada en el Artículo 1 de la Convención del Patrimonio Mundial, firmado en el año 1972. De esta manera, puntualizaron que estos lugares son "obras del hombre u obras conjuntas del hombre y la naturaleza así como las zonas, incluidos los lugares arqueológicos que tengan un Valor Universal Excepcional desde el punto de vista histórico, estético, etnológico o antropológico" (Unesco, 2005, p. 47). Asimismo, ahondan en la definición ordenando que: territarias 32 
Los paisajes culturales son bienes culturales y representan las 'obras conjuntas del hombre y la naturaleza' [...]. Ilustran la evolución de la sociedad humana y sus asentamientos a lo largo del tiempo, condicionados por las limitaciones $\mathrm{y} / \mathrm{u}$ oportunidades físicas que presenta su entorno natural y por las sucesivas fuerzas sociales, económicas y culturales, tanto externas como internas. (Unesco, 2005 , p. 48).

Estas visiones institucionales expuestas por la Unesco, acerca de este tipo de patrimonio cultural, se asemejan a lo que Guhl (2009) plantea sobre la conjugación entre espacio, tiempo y tipo de sociedad, lo cual vislumbra los diferentes escenarios paisajísticos que se transforman dependiendo de cada época o contexto. En este caso, el paisaje cultural cafetero visualmente es una muestra de asentamiento humano moldeado por condiciones físicas, cánones culturales, aspectos económicos y articulado con las presiones del mercado global.

Sin embargo, antecediendo al paisaje como escenario visualizador de valores culturales, políticos y económicos, es pertinente traer a colación el concepto de territorio, asumido como producción cultural en el espacio. Esta idea está sustentada en los postulados del geógrafo francés Claude Raffestin (1980), quien expresa que el espacio es la dimensión que antecede al territorio y que este último es producto de las relaciones entre actores en el espacio (territorialidad), generando así una serie de demarcaciones y significaciones simbólicas de los espacios

\section{territarias 32} 40 apropiación de tipo concreto y/o abstracto sobre el territorio por parte de los actores. Para precisar, el mismo autor señala que:

El territorio es un espacio en el que se ha proyectado trabajo, energía e información y que, en consecuencia, revela relaciones marcadas por el poder. El espacio es la "prisión original”; el territorio es la prisión que los hombres se dan a sí mismos. (Raffestin, 1980, p. 102).

Bajo esta perspectiva, se deduce que el territorio, como producto de la acción humana espacializada, es motivo de disputas e intereses de cualquier índole (estatal, gremial, comunitario, particular, entre otros). Por tal motivo, los ejercicios de poder estructurantes de las diferentes relaciones sociales entre actores locales, gremiales, estatales y multinacionales desencadenan múltiples disputas por el control, ordenamiento y orientación de los recursos naturales, así como de los valores culturales, sociales y productivos de las poblaciones, mediante la imposición de modelos políticos y económicos. Así, la declaratoria del PCCPH, aparte de ser una apuesta por patrimonializar los valores locales de la caficultura y exaltarlos como valores universales excepcionales de la humanidad, puede ser asumida como un programa de desarrollo económico basado en la perpetuación de un tipo de caficultura de carácter institucional y, paralelo a ello, incentivar el turismo cultural, al aprovechar los componentes culturales y naturales de una región históricamente cafetera y patrimonial. 
Siguiendo esta línea argumentativa, es pertinente exponer la territorialidad como mecanismo de producción territorial $(\mathrm{Na}-$ tes, 2007). No obstante, el territorio y los mecanismos como la territorialidad (producción) y la territorialización (delimitación) no son procesos homogéneos, puesto que una de las características de esta triada socio-espacial es que son multiescalares y multidimensionales. Es decir, escalarmente el territorio tiene manejos y representaciones diferenciadas, dependiendo del tipo que sea: íntimo, familiar, gubernamental y de alteridad (Monnet, 2003) y está estructurado según el tipo de actor y su posición social. Por su parte, el aspecto dimensional se define según las prácticas y discursos que se gestan en el territorio, entonces, existen territorios de carácter sagrado, productivos, patrimoniales, entre otros.

Lo anterior es pertinente a la hora de constatar la consolidación del paisaje caficultor, tanto en el nivel discursivo del patrimonio, como en el nivel experiencial de los actores locales. De esta manera, se tiene el papel de los abanderados del proyecto patrimonializador, quienes aunaron esfuerzos y recursos para representar un paisaje cultural con ciertas características geomorfológicas, políticas y económicas que están ligadas al café como producto y práctica, y quienes expusieron ante el mundo la imagen de un paisaje cultural cafetero homogéneo. Por otro lado, los actores reproducen un territorio objetivado en las unidades socio-espaciales, mediante diversas prácticas económicas, evidenciando así un paisaje agroproductivo heterogéneo y dinámico, debido a la introducción de otras lógicas productivas reflejadas en la ganadería y el turismo.

Teniendo en cuenta el dinamismo territorial del paisaje cultural cafetero, es acertado exhibir las fincas y haciendas ${ }^{2}$ categorizadas como unidades socio-espaciales de análisis. Este ejercicio de categorizar posibilita vislumbrar las configuraciones y reconfiguraciones de estas unidades que integran el sistema agroproductivo. No obstante, la parte etnográfica se edificó bajo la dimensión socioeconómica, compuesta por niveles estructurales objetivados en los sistemas de producción cafetero (tradicional y/o paradigmático), ganadero y turístico, y por niveles experienciales, reflejados en las diferentes prácticas económicas, precisamente en los usos y manejos del territorio.

En términos de la dimensión planteada con anterioridad, es indispensable recalcar el papel que cumplen los actores por medio de las prácticas encaminadas hacia lo económico. Las prácticas son realizaciones estructuradas por unas trayectorias subjetivas y bajo ciertas condiciones materiales de existencia que establecen un sistema de disposiciones habitus (Bourdieu, 2007), por lo que encierran un sentido más amplio que incluye niveles de representación que van más allá del plano de la ejecución pragmática. En esta medida, las prácticas son "esquemas de percepción, de apreciación y de acción" (Bourdieu, 2007, p. 151), que en este caso se proyectan hacia lo económico y que son los determinadores sobre los usos, manejos y concepciones tanto de los actores institucionales que planean el paisaje
${ }^{2}$ Existe una diferenciación en cuanto a las denominaciones de finca $y$ de hacienda. Desde el punto de vista de los actores locales, el atributo de mayor importancia para la distinción de estas unidades socio-espaciales es la extensión. La hacienda, por ejemplo, es la unidad que puede superar las cincuenta hectáreas. Se caracteriza, además, por estar estructurada bajo un sistema de corte empresarial, es decir, se aprecia una distribución de cargos (propietarios, administradores, mayordomos, patieros, obreros permanentes y temporales) con sus respectivos espacios (beneficiaderos o silos, bodegas, alimentaderos o cuarteles, instalaciones auxiliares). En dichos lugares se desarrollan las actividades correspondientes a un sistema agropecuario tecnificado - en este caso café o ganadería-. En contraste, la finca se rige mediante una organización productiva conformada por la familia. Aunque las familias se encargan del funcionamiento de las fincas, hay casos en los que los propietarios no trabajan la tierra directamente, por tanto, mediante procesos contractuales solventan las funciones de administración, siembra $y$ cosecha.

territarias 32

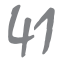


declarado como de los actores locales en sus unidades socio-espaciales.

Para hablar de prácticas de tipo económico es necesario mencionar los conceptos de previdencia y previsión (Bourdieu, 2006). Ambos conceptos se asumen de manera diferenciada. Por un lado, la previdencia se inscribe en el marco de una lógica que está ligada a normas o cánones culturales establecidos históricamente. El cálculo o la determinación económica está inscrita en la situación misma, en lo que cultural y materialmente se posee, en este caso es el café u otros productos, así como el conocimiento tradicional de las actividades agrícolas. Por otro lado, la previsión como práctica económica, está enmarcada en una lógica formal que en algunos casos hace parte del contexto local con la producción intensiva del café y/o con la actividad ganadera, mientras que en otros casos es ajena a las consolidadas históricamente, lo cual revela que hay toda una organización productiva que contiene otros componentes socioculturales y la proyección se estructura con base en esos componentes diferenciales, por ende, este tipo de prácticas escapa a los esquemas tradicionales que configuran las relaciones y las actividades económicas locales, tal como sucede con el turismo.

Lo anterior posibilitó la aproximación e indagación reflexiva de corte territorial $\mathrm{y}$, por consiguiente, el respectivo ejercicio etnográfico en dos aspectos. El primer aspecto menciona de manera crítica las proyecciones institucionales que giran en torno al paisaje patrimonial. El segundo aspecto hace referencia a la categorización y cla- sificación de las unidades socio-espaciales que integran el sistema territorial, con el objetivo de ubicar socialmente la dinámica intrínseca de la organización de cada unidad socio-espacial (finca y hacienda). En esta medida, categorizar - entendido como la naturaleza de los discursos, objetos o cosas-implica dotar la condición y cualidad de una cosa, mientras que el clasificar - entendido como la organización simbólica- es asumido como el ordenamiento y jerarquización del sistema (Nates, 2011).

\section{Relación entre el discurso patrimonial y el poder de la institucionalidad}

La declaratoria del PCCPH, al ser un patrimonio cultural de carácter localizado, fundado y gestionado desde la institucionalidad, requirió de personal especializado de diferentes sectores (academia, gremio y político) y recursos para su elaboración. Estos actores académicos, gremiales y políticos entraron en disputa por legitimar sus discursos, con el objetivo de ser reconocidos e iniciar la declaratoria. Así las cosas, "los poderes, si así puede llamárseles, o intereses, académicos compiten entre sí por certificar el rigor científico de las activaciones, por obtener reconocimiento social, recursos económicos, estatus" (Prats, 2005, p. 21).

Aunque Prats (2004) se centra en el campo académico, en la práctica también intervienen otros poderes, tal como sucedió con la declaratoria del PCCPH, la cual fue un escenario político en el que confluyeron discursos, recursos y estrategias de disciplinas 
de diversos campos del conocimiento, instituciones gubernamentales y gremiales, con el fin de negociar y en algunos casos imponer un tipo de paisaje reconocible, el cual fuese aprobado por la Unesco.

El PCCPH como proyecto para la exaltación de valores culturales e identitarios de una población, también es un ejercicio de poder estratégico para reordenar un territorio. Esta estrategia procura por la perpetuación de un tipo de práctica cultural o productiva, al mantener valores propios del contexto, con la incorporación de otras lógicas como el patrimonio, el mercado de bienes culturales y el turismo. Lo anterior se plantea con base en los postulados de Raffestin (1980), quien deja claro que el poder $^{3}$ como práctica social, basado en discursos, acciones y órdenes, permea toda relación entre actores, organizaciones, gremios, empresas multinacionales y demás instituciones (estatales y privadas). Por tanto, la apuesta de la declaratoria por conservar y preservar unos atributos asociados con el café, se puede asumir como una muestra de los intereses de la élite gremial y gubernamental por mantener este sector productivo bajo unos lineamientos institucionales en consonancia con el turismo cultural, lo que excluye a la representación de otros modos de relacionarse con el territorio, distintos a los plasmados en los expedientes que dieron soporte a la declaratoria.

Teniendo en cuenta lo anterior, se puede decir que el PCCPH no escapa a la triada relacional entre actores, territorio y poder. El ejercicio de seleccionar de manera consiente los atributos y componentes del siste- ma agroproductivo y hacer de él una representación patrimonial de carácter universal excepcional, llevó a las miradas y respectivas disputas entre diferentes actores (académicos, gremiales y gubernamentales) a definir qué atributos y criterios se incluían y cuáles se excluían, así como la delimitación de la zona principal y de amortiguamiento. Todo lo anterior, canalizado y debatido mediante relaciones de poder, resultado que llevó a la imposición de visiones institucionales sobre el cómo estructurar la declaratoria del paisaje patrimonial del poder.

\section{Elaboración de un tipo de PCCPH}

En el proyecto del PCCPH se puede percibir una serie de lineamientos que expresan el interés de múltiples instituciones por erigir un tipo de paisaje. En primera instancia, apareció el papel de académicos de múltiples disciplinas adscritos a las universidades de la región, ${ }^{4}$ los cuales procuraron - alrededor de una década iniciando en 2001 - valorar un tipo de PCCPH a partir de una amalgama de atributos de diversa índole. En segunda instancia, emergieron las aspiraciones de la FNCC para liderar este proyecto, tomaron lo trabajado por los académicos y al final lo estructuraron según sus intencionalidades, por tanto, se enfocaron en dar valor a la práctica cafetera, sostener un paradigma de actividad productiva, acorde a unos parámetros instaurados por ellos mismos, y exponer una cultura cafetera ante el mundo. No obstante, es importante mencionar que existió un acompa-
${ }^{3}$ Claude Raffestin (1980) trasciende el plano del poder en los aparatos estatales, la influencia de Michael Foucault lo inspiró para contribuir su geografía critica en torno a la influencia del poder en cualquier relación y a la par, en la importancia que tiene este ejercicio social en el ordenamiento del territorio, los recursos, la población, la educación, la guerra entre otros.

${ }^{4}$ En el proyecto trabajaron profesionales pertenecientes a disciplinas como arquitectura, antropologia, sociología, diseño, historia, economia, trabajo social, biologia, entre otras. Así mismo, este personal hace parte activa de las diversas instituciones de la región, entre ellas están la Red Alma Mater, que en su momento integró varias universidades de los departamentos de Caldas (Unal Manizales, U. de Caldas, $U$. Católica), Quindio (U. Quindio, La Gran Colombia), Risaralda (UTP, UCPR) y del Valle del Cauca (U. del Valle).

territorias 32

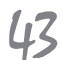


${ }^{5}$ Es importante recalcar este punto debido a que el estudio se desarrolló en Chinchiná, el cual es uno de los municipios cafeteros con mayor producción y además cuenta con una fuerte presencia de la institucionalidad cafetera.

${ }^{6}$ Al inicio en el año 2001 los departamentos que hacian parte del proyecto eran Antioquia, Caldas, Risaralda, Quindio, Tolima y Valle del Cauca. Sin embargo, a medida que transcurría el tiempo y se hacian las respectivas devoluciones de los expedientes por parte de la Unesco, provocó en los funcionarios de los departamentos de Antioquia y Tolima una desvinculación del proyecto.

\section{territarias 32}

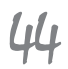

ñamiento por parte del Mincultura y demás entes territoriales tales como gobernaciones, corporaciones regionales y alcaldías, durante el trayecto en sus diferentes fases.

Aunque en el plan de manejo se expone la participación ciudadana en la consecución del bien patrimonial, es necesario afirmar que los actores locales habitantes de las fincas y haciendas del paisaje declarado no tuvieron una participación activa en el proyecto. Dicho esto, el plan de manejo expresa la participación de la sociedad civil mediante figuras organizativas como los comités técnicos regionales, los consejos municipal, departamental y nacional de cultura, las ONG y vigías del patrimonio, entre otros, los cuales contribuyeron a la formulación de los expedientes y del plan de manejo para la gestión y conservación (Rincón, 2012). Sin embargo, al decir que la participación de los actores locales fue mínima, se hace referencia a que los habitantes, agricultores, trabajadores, amas de casas, de las diferentes fincas y haciendas que hicieron parte del estudio ${ }^{5}$ desconocía de la declaratoria, excepto los actores locales dedicados al turismo en sus fincas y haciendas. Lo anterior obedece a la naturaleza de este patrimonio que, como dice Prats (2005), al ser de carácter localizado, la realización que se hace de este está en los universos formales de la academia, el gremio y el gobierno central.

La trayectoria de la declaratoria tuvo tres fases (2001-2005-2008) que fueron reflejo de cada etapa de formulación ante la Unesco. Los dossiers que objetivaron estas etapas se pueden asumir como mecanismos de producción territorial (territorialidad), ya que por medio de las discusiones entre los diferentes actores institucionales forjaron una serie de atributos que establecían el PCCPH; asimismo, estos atributos fungieron como derroteros para las delimitaciones simbólicas (territorialización) de las zonas principales y de amortiguamiento del sistema paisajístico. Todo lo anterior debió articularse con los criterios exigidos por la Unesco para declarar patrimonio de la humanidad los bienes culturales.

[V] Ser un ejemplo destacado de formas tradicionales de asentamiento humano o de utilización de la tierra o del mar, representativas de una cultura (o de varias culturas), o de interacción del hombre con el medio, sobre todo cuando este se ha vuelto vulnerable debido al impacto provocado por cambios irreversibles... [VI] Estar directa o materialmente asociado con acontecimientos o tradiciones vivas, ideas, creencias $\mathrm{u}$ obras artísticas y literarias que tengan una importancia universal excepcional. (El Comité considera que este criterio debería utilizarse preferentemente de modo conjunto con los otros criterios) (Unesco, 2005, pp. 54-55).

Tal como se puede observar, el criterio $\mathrm{V}$ exigido por la Unesco para iniciar la aprobación de declaratorias sobre paisajes culturales, hace pensar en una especie de urgencia social para llevar a cabo el proyecto patrimonializador. En esta medida, los representantes ${ }^{6}$ del gobierno central, gobernaciones, alcaldías, academia, corporaciones autónomas y gremio cafetero em- 
prendieron la búsqueda para solventar esta necesidad, por medio de la elaboración de múltiples estudios sobre el caso y proponer salidas para contribuir a la salvaguarda de la región, que según el análisis de expertos (PNUD, 2004), el eje cafetero entró en detrimento, primero, con un descenso del capital social y económico de miles de familias; segundo, los procesos de migración a otras ciudades que ocasionaron abandono del trabajo en la tierra; tercero, perdida de los valores y tradiciones de la caficultura tanto en prácticas culturales como en la práctica cafetera remitida a las actividades de explotación del grano. Lo anterior se debe a las crisis desatadas a finales de 1980 y que actualmente hacen parte de la dinámica de este sector agrario y, por tanto, según la mirada institucional, la declaratoria sería un proyecto de reivindicación cultural y al mismo tiempo un aliciente para consolidar otras alternativas económicas sostenibles diferentes al agro.

La declaratoria en sus tres fases se diferencia por las lecturas que hacen los actores institucionales sobre el territorio. En un primer momento, las aspiraciones de patrimonialización se enfocaron en postular un PCCPH mediante la valoración de la arquitectura urbana de los centros históricos de poblados con tradición cafetera y paisa (Mincultura, 2001). En un segundo momento, conformaron un equipo de trabajo interdisciplinario para ampliar la visión y comprensión de los componentes del paisaje, abarcando otras unidades temáticas (ambiental, histórica y cultural) (Mincultura, 2005). Sin embargo, ambos intentos fueron rechazados por la Unesco, pues no contaban cartográficamente con datos geográficos exactos y el seguimiento de los atributos no era el más adecuado.

La FNCC con el acompañamiento y respaldo del Mincultura construyó el expediente definitivo por el cual dieron vía libre a la declaratoria del PPCPH. En esta ocasión, el procedimiento fue realizado de manera rigurosa tal como lo exigía la Unesco, por tanto, intervinieron instituciones como el Centro Regional de Estudios Cafeteros y Empresariales (CRECE), quienes, con sus tecnologías referentes al campo cafetero, aplicaron las herramientas para estructurar el expediente final y llevar a cabo la medición de los atributos. Así, lograron levantar los planos cartográficos de la zona principal y de amortiguamiento debidamente georreferenciadas, dando prioridad a unas veredas y municipios del área, según los resultados de las mediciones (tabla 1$){ }^{7}$

La rigurosidad que exigió la Unesco pudo ser operable al contar con sistemas de información como el SICA. ${ }^{8}$ Esto permitió espacializar la medición de los atributos con el ánimo de establecer el área a declarar y respaldando la elaboración del expediente. Sin embargo, se puede observar que los demás atributos no se incluyeron en la medición, debido a la ausencia de sistemas de información que suministrarían dichos datos, cuestión fundamental para el aval de las declaratorias.

Por último, se destaca que la particularidad de la declaratoria se centra en la postulación de unos valores del PCCPH
7 "Este paisaje, identificado como bien cultural, se caracteriza por ser predominantemente rural comprendiendo 411 veredas en su área principal con un total de 140046 ba, frente al área principal urbana que cuenta con $1074 \mathrm{ha}$, 204542 ba para la zona de amortiguamiento rural $y$ 2458 en la zona de amortiguamiento urbana. Para el caso del departamento de Caldas, se identifican unas 78537 ha cultivadas del café, que corresponden al $35 \%$ del área total del PCCC, en las que se contabilizan 35683 caficultores y 42112 fincas cafeteras" (Mincultura, 2012, p. 43).

${ }^{8}$ El sistema de información cafetera (SICA) es una base de datos administrada por la Federación Nacional de Cafeteros, en la que se almacena información detallada sobre la producción de las diferentes fincasy haciendas cafeteras del pais.

territarias 32

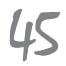


Tabla 1. Atributos finales

\begin{tabular}{|c|c|c|c|}
\hline Atributos seleccionados & Atributos seleccionados & Rango ponderado & Puntaje \\
\hline \multirow{3}{*}{ Café de montaña } & \multirow{3}{*}{$\mathrm{X}$} & $1000-1400 \mathrm{msnm}$ & 1 \\
\hline & & $400-1.800 \mathrm{msnm}$ & 2 \\
\hline & & > $1800 \mathrm{msnm}$ & 3 \\
\hline \multirow{4}{*}{ Predominancia del café } & \multirow{4}{*}{$\mathrm{X}$} & $<0,1 \%$ & 0 \\
\hline & & $0-30 \%$ & 1 \\
\hline & & $30 \%-60 \%$ & 2 \\
\hline & & $>60 \%$ & 3 \\
\hline \multirow{4}{*}{ Cultivo en ladera } & \multirow{4}{*}{$\mathrm{X}$} & $0-25 \%$ & 1 \\
\hline & & $25 \%-75 \%$ & 2 \\
\hline & & $75 \%-100 \%$ & 3 \\
\hline & & $>100 \%$ & 1 \\
\hline \multirow{4}{*}{ Edad de la caficultura } & \multirow{4}{*}{$\mathrm{X}$} & $0-2$ años & 3 \\
\hline & & $2-5$ años & 4 \\
\hline & & 5-9 años & 2 \\
\hline & & $>9$ años & 1 \\
\hline \multirow{2}{*}{ Patrimonio natural } & \multirow{2}{*}{$\mathrm{X}$} & Presencia & 1 \\
\hline & & Ausencia & 0 \\
\hline \multirow{2}{*}{ Disponibilidad hídrica } & \multirow{2}{*}{$\mathrm{X}$} & Presencia & 1 \\
\hline & & Ausencia & 0 \\
\hline \multirow{2}{*}{ Institucionalidad cafetera y redes afines } & \multirow{2}{*}{$\mathrm{X}$} & Presencia & 1 \\
\hline & & Ausencia & 0 \\
\hline Patrimonio arquitectónico & \multicolumn{3}{|l|}{ Sin medición } \\
\hline Patrimonio arqueológico & \multicolumn{3}{|l|}{ Sin medición } \\
\hline $\begin{array}{l}\text { Poblamiento concentrado y estructura de la } \\
\text { propiedad fragmentada }\end{array}$ & \multicolumn{3}{|l|}{ Sin medición } \\
\hline
\end{tabular}

\section{territarias 32}




\begin{tabular}{|c|c|c|c|}
\hline Atributos seleccionados & Atributos seleccionados & Rango ponderado & Puntaje \\
\hline Influencia de la modernización & \multicolumn{3}{|l|}{ Sin medición } \\
\hline Patrimonio urbanístico & \multicolumn{3}{|l|}{ Sin medición } \\
\hline Tradición histórica de producción de café & \multicolumn{3}{|l|}{ Sin medición } \\
\hline $\begin{array}{l}\text { Minifundio cafetero como sistema de propiedad } \\
\text { de la tierra }\end{array}$ & \multicolumn{3}{|l|}{ Sin medición } \\
\hline Cultivos múltiples & \multicolumn{3}{|l|}{ Sin medición } \\
\hline $\begin{array}{l}\text { Tecnologías y formas de producción sostenibles } \\
\text { en la cadena productiva del café }\end{array}$ & \multicolumn{3}{|l|}{ Sin medición } \\
\hline
\end{tabular}

Fuente: Paisaje cultural cafetero. Excepcionalidad fusión entre naturaleza, cultura y trabajo colectivo (2012, Mincultura).

que determinan la excepcionalidad del bien patrimonial, como estrategia para representar la imagen de un paisaje con unas características culturales, institucionales, económicas e históricas relacionadas al café como producto y práctica cultural. De esta manera, la institucionalidad cafetera afirma bajo el discurso patrimonial que el sistema paisajístico declarado bien de la humanidad fue moldeado y que actualmente es reproducido bajo estos valores socioculturales:

1. Trabajo familiar, generacional e histórico para la producción de un café de excelente calidad, en el marco de un desarrollo sostenible

2. Cultura cafetera para el mundo

3. Capital social estratégico construido alrededor de una institucionalidad

4. Relación entre tradición y tecnología para garantizar la calidad y sostenibilidad del producto (Mincultura, 2011)
Asimismo, expresan que la producción territorial en diversas dimensiones, llámese cultural, natural y económico, es única en comparación con otros bienes culturales de este tipo por su homogeneidad, tal como se expone a continuación:

El paisaje cultural cafetero de Colombia (PCCC) constituye un ejemplo sobresaliente de adaptación humana a condiciones geográficas difíciles sobre las que se desarrolló una caficultura de ladera de montaña. Se trata de un paisaje cultural en el que se conjugan elementos naturales, económicos y culturales con un alto grado de homogeneidad en la región, y que constituye un caso excepcional en el mundo. En este paisaje se combina el esfuerzo humano, familiar generacional de los caficultores con el acompañamiento permanente de la institucionalidad. Aunados, estos esfuerzos han establecido un modelo excepcional de acción colectiva que ha permitido superar circunstancias económicas territarias 32 
difíciles y sobrevivir en un paisaje agreste y aislado. (Mincultura, 2012)

Estas apuestas políticas dan a entender que la representación del paisaje caficultor, bajo el discurso patrimonial, contiene una alta carga de intereses del gremio por reproducir un tipo de caficultura y por reivindicar una actividad productiva que anda en paulatina decadencia. Mostrarle al mundo que el PCCPH es un bien excepcional universal por los atributos que lo definen, es buscar - en medio de las crisis económicas del sector y pérdida de la confianza en la institucionalidad cafetera- un culto a la mismidad y resaltar un estado providencial idílico, por medio de cadenas discursivas como la de la homogeneidad, el esfuerzo humano y el paisaje agreste y aislado. Esto, al invisibilizar de fondo un sector agroproductivo cafetero que atraviesa reconfiguraciones tanto a nivel territorial como socioeconómico, dado que el café viene perdiendo protagonismo por las múltiples crisis cafeteras.

\section{Relación entre patrimonio y el turismo}

Así como el patrimonio es una estrategia para consolidar un tipo de territorio, también es pertinente aseverar la relación que existe entre las declaratorias patrimoniales y el turismo. Parte del trasfondo del asunto patrimonial está estrechamente relacionado con reafirmar y fortalecer el desarrollo del turismo como una práctica productiva importante en el sistema económico local.
No obstante, el turismo no ocurrió con la declaratoria, esta actividad fue acuñada por muchos cafeteros como alternativa económica para la obtención de capitales que les ayudaran a resistir los contextos de crisis de producción. Sin embargo, uno de los propósitos implícitos de la declaratoria se orienta en buscar en el patrimonio cultural una oportunidad para que muchos cafeteros usufructúen el patrimonio cultural y familiar (tierras, cultivos, casa, saberes culturales), y consolidar el turismo en sus unidades socio-espaciales, tal como lo expresan académicos y representantes del gremio respectivamente:

Lo que queremos es usar a la Unesco para que nos declare y nos valore y lograr una cosa, y después de la cosa viene lo mejor, que es el desarrollo económico y social que a partir de eso tenemos que tener $[\ldots]$ finalmente, esto que nos va a traer desarrollo económico y social de la región a través del turismo, yo lo digo claramente, eso no hay que tener vergüenza en eso, hace un tiempo uno decía, $¡ A h$ ! es que hablar de plata en patrimonio que vergüenza, pa' eso es... (Sarmiento, Comunicación personal, 2014).

Capítulo especial merece el tema del turismo. La primera reacción que usualmente oímos de quienes se acercan a este proyecto es que el PCC constituye una inmensa oportunidad para atraer más visitantes que generen mayores ingresos a la zona. En este punto permítanme también hacer algunas reflexiones. En la Federación creemos que debemos pensar en una estrategia de turismo sostenible

Diego Alejandro Mayorga Castaño 
que genere valor al habitante rural, a quien tiene bajo sus hombros la responsabilidad primordial de sostener el paisaje. (Rincón, 2012, p. 12)

Reforzando la postura anterior, en torno al valor económico del patrimonio, el Ministerio de Industria, Comercio y Turismo del gobierno de Colombia concibe el territorio declarado como una oportunidad para proyectarlo como destino turístico de clase mundial. Esto se da por medio de una serie de estrategias discursivas y de inversión, tanto en el sector hotelero, infraestructura, comunicación, como en la capacitación a empresarios y población local interesada en promover diversas clases de turismo, tal como se puede observar en la tabla 2 .

Tabla 2. Visión y proyección institucional del PCCC

\begin{tabular}{|c|c|}
\hline Componente & Detalle \\
\hline Objetivo general & $\begin{array}{l}\text { Estructurar el producto } \\
\text { turístico del paisaje cultural } \\
\text { cafetero, enmarcado en las } \\
\text { potencialidades, oportunidades } \\
\text { y ventajas comparativas de los } 4 \\
\text { departamentos. }\end{array}$ \\
\hline $\begin{array}{l}\text { ¿Cuáles son las } \\
\text { estrategias? }\end{array}$ & $\begin{array}{l}\text { - Buen gobierno en el sector } \\
\text { - Infraestructura turística } \\
\text { - Conectividad aérea, marítima } \\
\text { - } \text { terrestre } \\
\text { - } \text { Estudios e investigaciones } \\
\text { - para el sector } \\
\text { - Competitividad de los } \\
\text { destinos y productos }\end{array}$ \\
\hline
\end{tabular}

Paisaje Cultural Cafetero, Patrimonio de la Humanidad

\begin{tabular}{|c|c|}
\hline Componente & Detalle \\
\hline $\begin{array}{l}\text { Proyectos } \\
\text { Sistema General } \\
\text { de Regalías Mesa } \\
\text { Paisaje Cultural } \\
\text { Cafetero y } \\
\text { Turismo }\end{array}$ & $\begin{array}{l}\text { - } \text { Implementación código } 4 \mathrm{C} \\
\text { en líneas. } \\
\text { - } \text { Relevo generacional } \\
\text { - Conservación y puesta en } \\
\text { valor del PCC } \\
\text { - Mantenimiento rutinario y } \\
\text { recuperación de vías } \\
\text { - Conocimiento y apropiación } \\
\text { del PCC } \\
\text { - Conectividad en zonas rurales } \\
\text { del PCC } \\
\text { - Mejoramiento de vivienda } \\
\text { rural con técnicas } \\
\text { constructivas tradicionales } \\
\text { - Rutas del café } \\
\text { - Sostenibilidad del café } \\
\text { colombiano por medio de las } \\
\text { denominaciones de Origen } \\
\text { del Café Regional y Marcas }\end{array}$ \\
\hline
\end{tabular}

Fuente: elaboración propia a partir de Convención sobre el Paisaje Cultural Cafetero. (Trabajo de Campo, 2012).

Se puede constatar que la declaratoria es utilizada como un medio propicio para generar mecanismos de inversión económica y proyectar territorialmente el turismo. Este nuevo rumbo traería un cambio en el uso del sistema territorial de las unidades socio-espaciales, puesto que estas fincas y haciendas, que otrora se orientaron exclusivamente para la explotación del grano, actualmente son proyectados también como sitios de destino turístico.

Así las cosas, La declaratoria institucionalizada entra en juego con el modelo neoliberal fundado en las economías flexibles (Harvey, 2007). Este modelo da prioridades a la dinámica del sistema financiero y demás actividades productivas que hacen parte del tercer sector de la economía

territarias 32

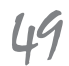


${ }^{9}$ Las definiciones que se presentarán de cada categoría socio-espacial obedecen a las enunciaciones establecidas por la coordinadora Béatriz Nates Cruz y el equipo del proyecto "Cartografía semiótica para la comprensión, análisis y monitoreo del Paisaje Cultural Cafetero como Patrimonio de la Humanidad. El caso de Caldas", las cuales fueron articuladas en la tesis de grado "Etnografía Territorial de los Procesos de Configuración y Reconfiguración del Paisaje del Café desde una Dimensión Socioeconómica. (Municipio de Chinchiná, Caldas Colombia)". En casos de citación se propone (Mayorga is Nates, 2014).

\section{territarias 32}

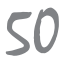

reflejadas en actividades como el turismo, comercio y comunicaciones. La práctica turística de tipo rural en las unidades socioespaciales está tomando protagonismo en contraste con la práctica cafetera, históricamente estructuradora de los modos de vida y de configuración territorial de estas regiones patrimonializadas. Lo anterior ha provocado reconfiguraciones de tipo territorial (fincas y haciendas como sitios de descanso), económico (cultura como comercio, instrumentalización de la cultura, relato de tradiciones) y de actores en niveles cognitivos (promotores de turismo, gestores, guías turísticos). No obstante, estas actividades no son acogidas por todos los actores locales y no son llevadas a cabo en todas las unidades socio-espaciales; para ello, los actores deben poseer unos capitales (tierras, dinero, sistema financiero) y un sistema de disposiciones habitus (acordes niveles de escolaridad, capital cultural y social) que estructuren y orienten este tipo de prácticas (Bourdieu, 2006).

\section{Mirada etnográfica en las unidades socio- espaciales del paisaje real}

Se considera la etnografía como uno de los múltiples campos del conocimiento, estrechamente ligada a la antropología y demás disciplinas encargadas de lo social. Los aportes que hace son de tipo contextual, mediante la observación directa (activa o pasiva), permeada por el pool teórico-conceptual y técnico los cuales son incorporados y utilizados por el investigador para la descripción y comprensión del fenómeno, brindando una mirada objetiva, al tener en cuenta el marco de referencia y los intereses del investigador. No obstante, el ejercicio etnográfico no se considera un método - bajo la definición clásica de las ciencias naturales-, por el contrario, se asimila como una forma de estar en el mundo de manera reflexiva (Tezanos, 1998).

Con el acercamiento a la zona rural de este municipio se busca evidenciar la dinámica socioeconómica de las unidades socio-espaciales. Por consiguiente, se hizo una tipificación de unidades socio-espaciales que dan cuenta de las prácticas económicas que se llevan a cabo en cada una de ellas. En esta medida, la categorización está compuesta por unidades socio-espaciales tradicionales, paradigmáticas, disidentes y de actividad mixta, las cuales sintetizan la realidad y permiten vislumbrar las respectivas configuraciones y reconfiguraciones territoriales.

\section{Unidades socio- espaciales tradicionales}

Las unidades socio-espaciales tradicionales se caracterizan por estar orientadas a las actividades agrícolas del café y otros productos. Particularmente "en esta unidad socio-espacial productiva se realizan prácticas agrícolas del cultivo del café en alternancia con otros productos. Es lo que se ha llamado en estos contextos, cultivos asociados con el café, principalmente plátano y frutales" (Mayorga \& Nates, 2014, p. 83$){ }^{9}$ 
Esta modalidad de cultivar se puede asumir como una de las manifestaciones tradicionales de la caficultura. Los cultivos que son diferentes al café se utilizan para la comercialización, el consumo familiar y, en cierto grado, como sombrío. Sin embargo, es pertinente aclarar que no se trata de un survival ${ }^{10}$ de la caficultura tradicional, debido a que estas prácticas de antaño se desarrollaban con otras técnicas y tenían otras finalidades. Además, no cultivan las variedades del sistema tradicional (arábigo, borbón, típica), así como la no utilización de abonos de origen orgánico compuestos por residuos de origen animal o vegetal. Por lo general, el café se siembra en surcos y los demás productos en barreras, y son unidades que son pequeñas en extensión territorial sin sobrepasar las tres hectáreas.

La categoría de unidad socio-espacial tradicional no corresponde a una organización productiva acorde al modelo de la caficultura tradicional de mediados del siglo pasado. En esta medida, las técnicas de sembrado son muestra de un modelo alterno al orientado por la FNCC, puesto que sus propietarios siguen ciertas pautas de esa institución, pero omiten el punto que trata la erradicación de los árboles que dan sombrío al café (frutales, plátano, aguacate, entre otros), ya que ven en estos bienes una opción extra de ingreso económico y también para el autoabastecimiento familiar. Tal como lo afirma el siguiente actor local, "el sombrío no es que afecte al café, yo no tumbo los árboles, lo que hago es aumentar el doble de abono en esa parte para que el árbol se coma una parte y el café lo que necesita” (Vallejo, 2013). Esto es una muestra de la conservación de ciertos rasgos culturales de la caficultura con sombrío, sin aseverar tácitamente que esto sea un retroceso, más bien es una estrategia para alternar la explotación de la tierra sin depender netamente del café.

Una particularidad económica de estas unidades socio-espaciales son las que están relacionadas con la renovación de cultivos. Algunos actores locales propietarios de la finca buscan otras opciones para llevar a cabo la fase de renovación de sus cafetales, y lo hacen por medio de la figura de arrendamiento del lote o tajo. Este contrato basado en la confianza consiste en la asignación del lote que será objeto de renovación a otro actor local (vecino y amigo), el cual será el encargado de cuidar el crecimiento de los árboles renovados hasta que empiecen a dar frutos. Mientras esto sucede, el arrendatario cuida y al mismo tiempo tiene la posibilidad de cultivar otros productos (frijol y/o habichuelas), diferente al café y los excedentes de las cosechas serán de su propiedad.

En síntesis, este tipo de unidades socioespaciales se caracterizan de la siguiente manera: primero, son unidades donde la producción territorial se orienta a la alternación de cultivos; segundo, una dependencia económica del cultivo del grano, con el complemento del plátano, fríjol, aguacate, cítricos entre otros; tercero, la trayectoria subjetiva de los actores locales, así como la permanencia y reactualización de los diversos espacios de la finca, lo cual expresa que son actores que están en el
${ }^{10}$ Concepto de la teoría evolucionista que trata sobre los rasgos o manifestaciones culturales que han sobrevivido en el tiempo y que se expresan de formagenuina. territarios 32

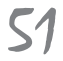


${ }^{11}$ Lasideas del autor citado se bicieron colectivamente entre Diego Mayorga y la asesora de la tesis Antropóloga Béatriz Nates Cruz.

\section{territarias 32}

marco de la previdencia (Bourdieu, 2006). En el sentido de que la práctica económica está estructurada por lo que materialmente se posee (café y/o otros productos), al mismo tiempo que son orientados por los conocimientos de la caficultura en la tendencia local.

\section{Unidades socio-espaciales paradigmáticas}

Las unidades paradigmáticas se definen por el predominio implícito del café. Pues bien, "en esta unidad socio-espacial productiva el café constituye un monocultivo. No obstante, pueden existir focos aislados de diversificación agrícolas en frutales particularmente, sin que esto genere impacto en la estructura productiva dedicada exclusivamente al café" (Mayorga, 2014, p. 90). ${ }^{11}$ Lo anterior refleja la organización socio-espacial de la producción, lo cual sustenta la categorización de estas fincas o haciendas, ya que se objetiva un tipo de configuración territorial estructurada por el monocultivo del café, lo que refleja, de esta manera, el paradigma de producción propuesto por la FNCC.

La configuración territorial basada en el monocultivo da cuenta de la reproducción de los cánones institucionales del cultivo tecnificado. Los actores locales ponen en marcha los lineamientos que impone Cenicafé, quienes son los que proponen una siembra netamente a exposición solar sin interrupción causada por el sombrío, además, esta práctica debe estar reforzada por medio de la utilización de fertilizantes y fungicidas agroquímicos para un mayor desempeño.

Sin embargo, existen otros cultivos aparte del café, pero con menor incidencia en la estructura productiva. Estos cultivos secundarios son sembrados de forma aislada sin entorpecer el monocultivo y su finalidad se basa en la obtención de algún producto para la alimentación de la familia, vecinos y/o trabajadores. El plátano es el producto más concurrido, al igual que la yuca, frutas, cítricos, entre otros.

La configuración territorial de estas unidades denota la exteriorización de un habitus que está en el marco de la lógica de la previsión (Bourdieu, 2006). Esta modalidad responde a expresiones de actores que reproducen las prácticas agrícolas de la caficultura en monocultivo, sin estar aferrados a rasgos que se derivan de los usos y manejos tradicionales (sombríos, arriendo de predios, cultivos intercalados, entre otros), ya que han introducido y acoplado en todos los espacios de fincas y haciendas las plataformas técnicas de la caficultura intensiva tecnificada.

Estas unidades socio-espaciales de la previsión agrícola tienen una configuración territorial en niveles espaciales, productivos y organizacionales, acorde a lo empresarial como unidades productoras a gran escala. Así mismo, organizar una estructura jerárquica bien demarcada les permite a los propietarios delimitar social y espacialmente todo los miembros del sistema productivo, permitiéndoles, de esta manera, aprovechar los recursos culturales y naturales, con el fin de optimizar los dividendos y poder sobre- 
llevar las diversas crisis que se dinamizan en el campo de la caficultura.

\section{Unidades socio- espaciales disidentes}

El caso de las unidades socio-espaciales disidentes obedece al rompimiento estructural con el sistema de explotación imperante. Es decir:

[...] esta unidad socio-espacial rompe con el modelo productivo de la caficultura. Se trata de unidades donde sus parcelas ya no están cultivadas con café. Son unidades de considerable extensión (entre 100 y 500 hectáreas) que tienen generalmente un nuevo sistema productivo basado en la ganadería, lo cual ha reconfigurado el territorio tanto en su actividad tradicional, como en la configuración y ocupación socio-espacial del conglomerado que la constituía tradicionalmente cafetera (casa de agregado, cuarteles, beneficiaderos, etc.) (Mayorga, 2014, p. 98).

Estas unidades socio-espaciales vienen adelantando procesos de sustitución del café por la introducción de ganadería. Lo anterior se debe a las fluctuaciones económicas que acarrea el cultivo, puesto que para el desarrollo de esta producción a gran escala, el propietario - que en este caso no vive en la hacienda - tenía que disponer de una cantidad considerable de inversión de capital, que era destinado a subsanar los costos de la producción, tanto en mano de obra como en insumos para el procesado del café. Lo que generaba, de esta manera, cambios en la orientación productiva de estas haciendas que tradicionalmente eran cafeteras, y que son reflejo del estado actual de la caficultura a gran escala.

Las condiciones del nivel estructural de la dimensión socioeconómica incidieron en el desencadenamiento de las nuevas prácticas productivas a nivel experimental. Por lo tanto, después de ser reiterativos los periodos de crisis, y sumándole a ello la inversión fitosanitaria que exige el cultivo y la poca rentabilidad que obtenían de ello, los propietarios se vieron impulsados por optar alternativas distintas al café y fue así como iniciaron la inclusión gradual de pastos para la cría de ganado. Se entiende que estos procesos son mecanismos de adaptación, según las circunstancias externas y locales que atraviesan los territorios y sus habitantes. Por esta razón, estas haciendas ganaderas son otro componente importante que empieza a coger fuerza en el paisaje del café y que han desencadenado reconfiguraciones, tanto en lo territorial como en lo socioeconómico.

Una de las reconfiguraciones más relevantes se da en los espacios de producción, lo que muestra la transición entre una hacienda cafetera paradigmática a una hacienda ganadera de naturaleza disidente. Estos espacios se ven reconfigurados en su morfología y uso. En términos morfológicos, el territorio que estaba conformado por una cantidad considerable de árboles de café exigía una ordenación espacial y organizacional basada en lo empresarial de tipo agrícola, ahora se puede percibir un territorio compuesto por ganado y con poco territarias 32

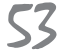


personal de trabajo operando bajo otras racionalidades. Así mismo, los usos de los espacios para el procesado y almacenado también se vieron transformados por este nuevo panorama, puesto que los beneficiaderos, en donde se procesan los granos maduros de café y se hace el posterior acopio en las bodegas de almacenamiento, se reconfiguraron en un no uso de estos. Con la introducción de pastos, y por consiguiente de ganado, los espacios del café pasaron a ser espacios de la ganadería. Este fenómeno actual, aparte de reconfigurar el café como grano, también refleja la erradicación de los valores culturales y económicos de la caficultura tecnificada, propias de las grandes haciendas que fueron el motor de la bonanza cafetera en la década del setenta (Narváez \& Vargas, 2007), caso concreto la hacienda La Francia.

En síntesis, estas haciendas pasan de ser categorizadas como unidades paradigmáticas para ser categorizadas como unidades disidentes, lo que deja a su paso múltiples reconfiguraciones. No obstante, lo que en esencia conserva es la organización hacia la racionalidad económica, logrando, de esta manera, el funcionamiento sistemático de la hacienda. Sin embargo, no hay que desconocer que el trabajo en términos cualitativos y cuantitativos sí se vio reconfigurado radicalmente. Por un lado, pasar de ser una plataforma territorial para trabajadores de café a una plataforma para trabajadores del ganado infiere en las estructuras cognitivas de los actores, mientras que, por otro lado, el cambio de producción afectó el número de trabajadores, el cual disminuyó de 300 trabajadores promedio, entre permanentes e itinerantes, a 3 empleados permanentes, suma considerable que indica el impacto socioeconómico deplorable en el capital social el cambio de actividad productiva.

\section{Unidades socio-espaciales de actividad mixta}

Las unidades socio-espaciales de actividad mixta se caracterizan por la realización de prácticas económicas ligadas a la agricultura y el turismo. De este modo, se plantea que:

Esta unidad socio-espacial productiva constituye la objetivación de la bifurcación socioeconómica del paisaje agrario del café. Son fincas de múltiples servicios: turismo (eco-hoteles, fondas, etc.), parcelas diversificadas, donde el café constituye un producto para ofrecer como cultura y como grano. (Mayorga, 2014, p. 104).

Por tanto, estas unidades que históricamente han sido orientadas para la explotación y comercialización de café, ahora están siendo objeto de reconfiguración territorial y económica para el ofrecimiento del turismo rural, convirtiendo estas fincas y haciendas en destinos para el descanso y el esparcimiento.

El turismo rural en las fincas y haciendas de Chinchiná emergió como actividad económica hace aproximadamente una década, lo que da a entender que no es consecuencia de la declaratoria del PCCPH. Ello tiene sus bases a partir de los cambios políticos y económicos del orden mundial, 
por la incursión del modelo neoliberal en asocio con la globalización (Harvey, 2007). Teniendo en cuenta este nuevo orden socioeconómico, los propietarios de fincas y haciendas, así como empresarios del sector de los servicios, vieron en el turismo una opción acertada de lucro en estas regiones, aprovechando los entornos naturales y los valores culturales de sus poblaciones. Por tanto, en Chinchiná surgen proyectos conocidos como la finca Colina del Sol y la hacienda El Sinaí, consideradas unidades agrícolas para el café y, al mismo tiempo, destinos turísticos.

Estas unidades socio-espaciales, al ser insertadas en la lógica de la actividad turística, generan una serie de transformaciones espaciales en distintos niveles y dimensiones. En esta medida, la casa, así como los demás espacios circundantes, pasan de ser de uso exclusivo de la familia a ser de uso público para los turistas que deseen hospedarse y pagar por ello. Es así como las escalas espaciales de lo privado y lo público se traslapan a medida que la unidad es frecuentada por viajeros, por lo tanto, esos espacios cotidianos de la vivienda: habitaciones, salas, pasillos, cocina, entre otros, quedan al orden de la oferta para que sean usadas por los clientes. Otra de las reconfiguraciones de estas unidades se objetiva por medio de la construcción de instalaciones adicionales como hostales y barbecue. Tanto en la finca Colina del Sol como en la hacienda El Sinaí, se observan estos procesos de ampliación infraestructural, lo cual es un rasgo que evidencia una consolidación del turismo como actividad próspera ahora en el marco de la declaratoria.

Es claro que la reconfiguración territorial no queda anclada al plano morfológico de los espacios. También se relacionan aquellas reconfiguraciones que están en el plano de la semantización y que articulan al mismo tiempo otros usos. Es el caso del proyecto que se lleva a cabo en la hacienda El Sinaí. Allí el promotor acondicionó la antigua fonda de su abuelo y la transformó en un espacio en el que el turista puede conocer la historia familiar, por medio de los diferentes objetos, al mismo tiempo, consumir bebidas como gaseosas, cervezas y café. También en la finca Colina del Sol se llevan a cabo estos procesos, el propietario de esta unidad exhibe los objetos familiares y concernientes al desarrollo de la caficultura de antaño. Lo anterior se puede concebir como un turismo de la memoria en estos lugares donde se evoca el pasado mediatizado por una transacción económica y posibilitando lo que se conoce como capitalismo cultural.

Estas reconfiguraciones son una exteriorización de la lógica de previsión y, más precisamente del habitus, de estos actores locales, los cuales han articulado esta lógica económica alterna a las que estructuran las actividades agrícolas (previdencia y previsión agrícola) (Bourdieu, 2006). Por tanto, estas nuevas dinamizaciones socioeconómicas ocasionan el surgimiento de otra clase de actor local que, en últimas, es el que aprovecha económicamente la declaratoria y el turismo, inclinándose más hacia la 
prestación de este servicio y relegando la administración y operatividad del cultivo del grano y demás productos a familiares o personal contratado.

En síntesis, este tipo de unidades socioespaciales de actividad mixta representan lo que se ha denominado desde el Grupo de Investigación Territorialidades, procesos de bifurcación socioeconómica, que consiste en la combinación de actividades agrícolas del café (tradicional y paradigmático) y del servicio turístico, las cuales, por su naturaleza, son prácticas económicas diferenciadas pero que se desarrollan bajo esta unidad socio-espacial y constituyen un sistema territorial particular: las fincas y haciendas agro-turísticas. Estas unidades socio-espaciales de actividad mixta son una muestra de la dinamización contemporánea del agro, lo que hace pensar que la inclusión de nuevas apuestas económicas para mitigar, en cierta medida, la debacle progresiva de este sector productivo genera unas reconfiguraciones en todas las dimensiones de la realidad (territorial, económica, social, política). Esto provoca nuevas concepciones - locales e institucionales-, tanto en la práctica como en el discurso, acerca de la dinámica socioeconómica, el territorio y los actores de los paisajes agroproductivos patrimonializados.

\section{Conclusiones}

Tal como se dijo anteriormente, la declaratoria del PCCPH es una estrategia políticoeconómica para consolidar un tipo de te-

\section{territarias 32}

de un paisaje agroproductivo preponderantemente cafetero es reflejo de los intereses institucionales de la FNCC y el Mincultura por reivindicar, conservar y preservar unos valores universales excepcionales auténticos e integrantes, buscando así la recuperación de la confianza institucional, la perpetuación de una práctica cultural y económica institucionalizada que en las últimas décadas ha decrecido paulatinamente. Por lo tanto, estas apuestas políticas implican una serie de configuraciones y reconfiguraciones territoriales evidenciadas en la consolidación de un tipo de caficultura (institucional o paradigmática), complementada con el turismo rural como valor agregado a las zonas declaradas, expresadas en las unidades socio-espaciales de actividad mixta.

El discurso del PCCPH es una expresión del modelo neoliberal ejecutado en el territorio, acorde a las dinámicas del sistema capitalista. Tal como lo afirma Guhl (2009), los paisajes son los escenarios de reproducción dinámica de valores, políticas y condiciones económicas enmarcadas en la sociedad. En esta medida, se efectúa un tránsito entre un paisaje dedicado netamente a las prácticas agrícolas del café y de otros productos, a un paisaje agro-turístico consolidado territorialmente por prácticas económicas mixtas, balanceándose entre el café y el turismo como una alternativa en medio de múltiples crisis de este sector. Por tanto, articular esta región en la lógica de la tercerización de la economía bajo las modalidades del turismo, mercancías culturales, instrumentalización de la cultura, entre otros, ocasionaría un giro en la orientación 
productiva de miles de fincas y haciendas, lo que genera un desarrollo desigual entre los cafeteros.

La dimensión socioeconómica de la zona declarada está atravesando procesos de transformaciones, rupturas y bifurcaciones, tanto en lo estructural como en lo experiencial. Esta serie de fenómenos sociales se objetivan en las unidades socio-espaciales. Por tanto, la relación entre las condiciones objetivas de los sistemas productivos (caficultura, ganadería y turismo) y las intencionalidades subjetivas de los actores locales han generado unos tipos de prácticas económicas que provocan la estructuración de unidades cafeteras (tradicional y paradigmático), ganaderas (disidentes) y agro turísticas (de actividad mixta), acarreando unos tipos de configuraciones y reconfiguraciones territoriales, tanto en lo morfológico como en lo semántico. Esta forma de proceder posibilitó realizar el contraste entre el paisaje bajo el discurso del PCCPH expuesto mundialmente y el paisaje heterogéneo del municipio de Chinchiná - históricamente cafetero y con fuerte presencia institucional del gremio- con sus dinámicas económicas particulares. Arrojando como resultado un panorama en donde los productores de café, a medida que pasan los días, siguen viviendo periodos de crisis y resistiendo las secuelas de estas; los grandes hacendados están cambiando el café por el ganado y unos pocos cafeteros ven en el turismo una alternativa para sobrevivir en el contexto rural. Todo ello en un paisaje vivo y en contexto patrimonial.
Al hacer un acercamiento al paisaje, tanto al nivel del discurso patrimonial como al nivel socio-espacial, se genera una idea sobre las coherencias y contradicciones entre estos niveles. Teniendo en cuenta el marco de la declaratoria, los atributos y los valores que estructuran este bien universal, se pueden ver los casos en los que se contradice y se obedece al discurso. En primera instancia, se tienen las unidades socio-espaciales tradicionales, las cuales se caracterizan por una práctica cafetera asociada con otros cultivos y bajo ciertas técnicas que reflejan rasgos de la caficultura tradicional, escapando, en cierta medida, a las instauradas por la FNCC, mientras que las unidades socio-espaciales disidentes son la muestra de la ruptura con el café al ser reemplazado por el ganado. En segunda instancia, están las unidades socio-espaciales paradigmáticas, —categorizadas así por su organización productiva y basadas en el monocultivo - estas objetivizan la reproducción del paradigma de la FNCC. Asimismo, las unidades socio-espaciales de actividad mixta que, aparte de ser orientadas para la explotación del grano (tradicional y/o paradigmático), también se articulan a la lógica de la declaratoria, al ser fincas y haciendas de descanso (eco-hoteles, hostales, entre otros) y lugares donde se exhibe la cultura cafetera por medio del patrimonio familiar.

Por último, esta reflexión aporta un panorama sobre algunas dimensiones de la realidad que hacen parte del paisaje cafetero representado bajo el discurso del PCCPH. 
Aunque la naturaleza de la declaratoria sea de carácter localizado o, en otras palabras, administrado y gestionado por la institución, se debe tener en cuenta — para futuros aportes - una participación más activa de los actores locales, quienes son los que reproducen el territorio por medio de mecanismos como las territorialidades. Asimismo, se debe tener en cuenta que la imagen del paisaje construida en la declaratoria del PCCPH debe pasar por algunos ajustes en su andamiaje, con el fin de ser más incluyente con las dinámicas de un paisaje cafetero marcadamente más heterogéneo, debido al bajo protagonismo del café, la alta demanda del turismo cultural y los efectos de la ganadería en una zona históricamente agrícola y cafetera.

\section{Referencias}

Bourdieu, P. (2006). Argelia 60. Estructuraseconómicas y estructuras temporales. Buenos Aires: Siglo XXI.

Bourdieu, P. (2007). El Sentido Práctico. Buenos Aires: Siglo XXI.

Guhl, A. (2009). Café y cambio de paisaje en Colombia, 1970-2005. Medellín: Fondo Editorial Universidad EAFIT.

Harvey, D. (2007). Breve historia del neoliberalismo. Madrid: Akal.

Mayorga, D. (2014). Etnografía Territorial de los Procesos de Configuración y Reconfiguración del Paisaje del Café desde una Dimensión Socioeconómica. (Municipio de Chinhiná, Caldas Colombia). Facultad de Ciencias Jurídi- cas y Sociales, Universidad de Caldas. Manizales

Ministerio de Cultura. (2005). Coffee cultural landscape. Bogotá: Ministerio de Cultura.

Ministerio de Cultura. (2001). Paisaje cultural cafetero. Bogotá: Ministerio de Cultura.

Ministerio de Cultura. (2012). Paisaje cultural cafetero excepcionalidad fusión entre naturaleza, cultura y trabajo colectivo. Bogotá: Escala S.A. Inti Alonso.

Ministerio de Cultura. (2011). Paisaje cultural cafetero: Un paisaje cultural productivo en permanente desarrollo. Bogotá: Nomos Impresores.

Monnet, J. (2003). Las escalas de la representación y manejo del territorio. En B. Nates, Memorias ler seminario internacional sobre territorio y cultura (pp. 109-121). Quito: Abya-yala.

Narváez, D., \& Vargas, B. (2007). Racionalidad Campesina y Estrategias Sociales de los Caficultores Caldenses. Revista Virajes, 9, 257-289.

Nates, B. (2011). La Territorialización del Conocimiento, categorias y clasificaciones culturales como ejercicios antropológicos. Barcelona: Anthropos.

Nates, B. (2007). Territorios. En A. Baraño, J. L. García, M. Cátedra, \& M. J. Devillard, Diccionario de Relaciones Interculturales: Diversidad y Globalización. Madrid: Complutense.

PNUD. (2004). Eje Cafetero. Un pacto por la región informe regional de desarro- 
llo humano. Manizales: LitoCamargo Ltda.

Prats, L. (2004). Antropología y patrimonio. Barcelona: Ariel S.A.

Prats, L. (2005). Concepto y gestión del patrimonio local. Cuadernos de antropología social, 9, 17-35.

Raffestin, C. (2011). Por una Geografía del Poder. Michoacán: Colegio de Michoacán.

Rincón, F. (2012). Memorias Taller Técnico "El Paisaje Cultural y su Territorio". Manizales: Artes Gráficas Tizan Ltda.
Tezanos, A. (1998). Una etnografía de la etnografía: aproximaciones metodológicas para la enseñanza del enfoque cualitativo-interpretativo para la investigación social. Bogotá: Antropos.

Unesco. (2005). Directrices prácticas para la aplicación de la convención del patrimonio mundial. París: Fondos extraspresupuestarios españoles. 
